\title{
Cerebellopontine Angle Tumors; Tumor Size and Surgical Outcome
}

\author{
Mazin S Mohammed Jawad* \\ Department of neurosurgery, Private nursing home hospital, Iraq
}

Submission: March 03, 2017; Published: May 04, 2017

*Corresponding author: Mazin S Mohammed Jawad, Department of Neurosurgeon, Private nursing home hospital, Iraq, Tel: 009647706229469; Email: mazinsaad11@Gmail.com

\begin{abstract}
Object: Our object is to illustrate the various aspects of clinical presentation and surgical complications with linkage to the tumor size regarding cerebellopontine angle (CPA) tumors.

Materials and method: This is a prospective study of 30 patients at the Neurosurgical department / Medical city, with mean age of 36 years with CPA tumors (predominantly acoustic neuroma) that underwent surgical removal using a suboccipital retrosigmoid approach over a 1-year period (2015 / 2016).

Results: There was a female preponderance. The most common presentation was vertigo followed by tinnitus. There were two cases (6\%) of cerebrospinal fluid leak. Facial nerve function was measured by the House Brackmann (HB) system and function further classified into three categories: excellent (HB I-II), intermediate (HB III-IV), and poor (HB V-VI) outcome following surgery, showing that all cases below $20 \mathrm{~mm}$ tumor size have an excellent outcome and (67\%) of cases with $>20 \mathrm{~mm}$ tumor size shows poor outcome. One death in this study (mortality rate, $3 \%$ ) was due to respiratory cessation.
\end{abstract}

Conclusion: Significant correlation between tumor size and facial nerve outcome, with larger C.P.A. tumors yield worse outcomes. Tumor size also influences the development of CSF leak and operative morbidity and mortality.

Keywords: Cerebellopontine angle tumors; Facial nerve; CSF leak

\section{Introduction}

Cerebellopontine angle (CPA) tumors are the most common neoplasms in the posterior fossa, accounting for $10-15 \%$ of intracranial tumors. Most CPA tumors are benign, with 80-94\% being vestibular schwannomas (acoustic neuromas), lipomas, vascular malformations, and hemangiomas. The most frequent nonacoustic CPA tumors are meningiomas (3-10\%), epidermoids (primary cholesteatomas) (2-4\%), and facial or lower cranial nerve schwannomas. Primary malignancies or metastatic lesions account for less than $2 \%$ of neoplasms in the CPA [1]. Early in the 20th century, CPA lesions were difficult to diagnose and rarely completely excised. Indeed, the mortality rate for operative intervention in the posterior fossa approached 50\%. However, revolutionary advances in neuroradiologic imaging and surgical techniques and approaches have made these lesions almost uniformly treatable with acceptable morbidity and very low rates of mortality. Surgical intervention remains the most definitive means for complete tumor removal for most of these lesions. Radiation therapy has gained popularity to arrest tumor growth with specific tumor types and is also an option for patients who are unwilling or medically unable to undergo surgery [2].
There is tendency for patients diagnosed with vestibular schwannoma to be white, aged 50-60 years, and in a professional occupation, but there seemed to be no specific sex preference in the disease. A strong association appeared to exist between hay fever and vestibular schwannoma, while tobacco use seemed to have an inverse relationship to the likelihood of developing the condition [3]. Surgical approaches vary depending on the pathologic entity as well as the size and involvement of adjacent structures. Although complete excision is planned for most cases, the intimate involvement of surrounding structures may impose unwarranted morbidity if complete excision is attempted. Meningiomas are excised completely more readily than epidermoids, whereas adequate therapy for arachnoid cysts is drainage [4]. Standard approaches to the CPA include the translabyrinthine, suboccipital (retrosigmoid), or middle fossa craniotomies (see Skull Base, Acoustic Neuroma (Vestibular Schwannoma). The choice of approach is based on specific location and hearing status. Occasionally, these craniotomies can be combined or performed in addition to an infratemporal fossa dissection for larger tumors [4]. The outcome and prognosis 


\section{Open Access Journal of Neurology \& Neurosurgery}

for cure from surgical resection depends on the histology, size, and location of the tumor and the approach chosen. Cessation of tumor growth from primary radiation also depends on the specific factors listed above. Expected facial palsy rates are high for primary facial schwannomas. The effect on quality of life from facial nerve palsy is quite significant. Results also depend on the experience and skills of the surgeon [5].

\section{Material and Methods}

This is a prospective study of 30 patients at the Neurosurgical department / Medical city between Sept. 2015 and Sept. 2016, were carried out and undergoing surgical removal using the suboccipital retrosigmoid approach. MRI Was done for all patients for the radiological diagnosis. The data collected in each patient included the patient's age, gender, size of tumor and postoperative complications. Tumors sizes divided into 3 categories $(1-10 \mathrm{~mm}, 11-20 \mathrm{~mm},>20 \mathrm{~mm})$ and pre operative symptoms was categorized in relation to the tumor size. Facial nerve function was graded according to the House Brackmann scale (HB) after surgery and allocated into three categories: excellent (HB I-II), intermediate (HB III-IV), and poor (HB V-VI) outcomes.

\section{Results}

A. 30 patients with a mean age of 36 years (range, 20-65 years) were included in this study. The histopathological diagnosis of CPA tumors in which acoustic neuroma represents $70 \%$ of all cases followed by meningioma $20 \%$ while epidermoid cyst, astrocytoma and lipoma represented in $10 \%$ of cases. There is an overall female predominance (60\%), $\chi 2$ (10.1816) and P-value (0.006153) at $\mathrm{p}<0.05$ which is significant statistically.

B. MRI Was done for all patients for the radiological diagnosis. The suboccipital retrosigmoid approach was the standard procedure in all cases described in our study.

C. The mean tumor size was $18 \mathrm{~mm}$, ranging from $<10 \mathrm{~mm}$ to $>20 \mathrm{~mm}, \chi 2$ (11.2667) and P-value (0.023725) at $\mathrm{p}<0.05$ as shown in Figure 1.

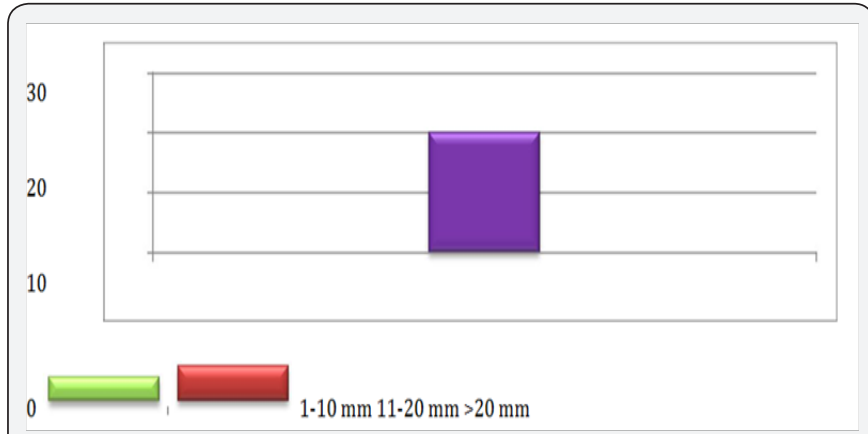

Figure 1: Shows distribution of tumors by size

i. 2 (11.2667), P-value (0.023725), p < 0.05

D. In our study we found that twenty three patients (76.6\%) presented with vertigo while tinnitus presented in 14 patients
(46.6\%). In both previous groups, the majority of patients (25 patients) had tumors with $11-20 \mathrm{~mm}$ in maximum diameter. Five patients had facial palsy preoperatively with mean tumor size of $20 \mathrm{~mm}$. This is statically significant $\chi 2$ (13.9751) and P-value (0.007375) at $\mathrm{p}<$

\section{a. (Table 1).}

Table 1: Shows patients preoperative symptoms in relation to tumor size.

\begin{tabular}{|c|c|c|c|}
\hline Tumor Size & Vertigo & Tinnitus & Facial Palsy \\
\hline $1-10 \mathrm{~mm}(4)$ & 3 & 1 & 0 \\
\hline $11-20 \mathrm{~mm}(20)$ & 15 & 10 & 1 \\
\hline$>20 \mathrm{~mm}(6)$ & 5 & 3 & 4 \\
\hline Total $(30)$ & $23(76.6 \%)$ & $14(46.6 \%)$ & $5(16.6 \%)$ \\
\hline
\end{tabular}

E. $\chi 2$ (13.9751), P-value (0.007375), $\mathrm{p}<0.05$.

F. Facial nerve function was graded according to the House Brackmann scale (HB) after surgery. Function was further classified into three categories: excellent (HB I-II), intermediate (HB III-IV), and poor (HB V-VI) outcomes. Twenty-five patients had an excellent and $4 \mathrm{had}$ a poor facial nerve functional outcome. All cases below $20 \mathrm{~mm}$ tumor size have an excellent outcome and (67\%) of cases with $>20 \mathrm{~mm}$ tumor size shows poor outcome this is of great significance, $\chi 2$ is 22.272 , the $p$-value is 0.000015 at $p<0.05$. The results are summarized in (Table 2).

Table 2: Tumor size and facial nerve outcome post operatively (by House-Brackmann grade)

\begin{tabular}{|c|c|c|c|c|c|c|}
\hline & \multicolumn{2}{|c|}{ Excellent } & \multicolumn{2}{c|}{ Intermediate } & \multicolumn{2}{c|}{ Poor } \\
\hline $\begin{array}{c}\text { Tumor } \\
\text { size }\end{array}$ & $\begin{array}{c}\text { Grade } \\
\mathbf{1}\end{array}$ & $\begin{array}{c}\text { Grade } \\
\mathbf{2}\end{array}$ & $\begin{array}{c}\text { Grade } \\
\mathbf{3}\end{array}$ & $\begin{array}{c}\text { Grade } \\
\mathbf{4}\end{array}$ & $\begin{array}{c}\text { Grade } \\
\mathbf{5}\end{array}$ & $\begin{array}{c}\text { Grade } \\
\mathbf{6}\end{array}$ \\
\hline $\begin{array}{c}1-10 \\
\mathrm{~mm}\end{array}$ & 4 & & & & & \\
\hline $\begin{array}{c}11- \\
20 \mathrm{~mm}\end{array}$ & 14 & 6 & & & & \\
\hline$>20 \mathrm{~mm}$ & 1 & & & & 4 & \\
\hline
\end{tabular}

G. $\chi 2$ is 22.272 . The $p$-value is $0.000015, \mathrm{p}<0.05$.

$\mathrm{H}$. There is a significant correlation between tumor size and facial nerve outcome, with larger tumors yielding worse outcomes. Table 2 illustrates this relationship, comparing facial nerve outcome with tumor size.

I. CSF leakage occurred in two patients (6\%).These cases were handled conservatively with application of wound dressing and bed rest the mean tumor size in patients with CSF leaks was $25 \mathrm{~mm}$, compared with $15 \mathrm{~mm}$ in patients without CSF leaks, $\chi 2$ is 8.5714 , the p-value is 0.003415 at $\mathrm{p}<0.05$ this give a strong evidence of correlation between tumor size and CSF leak.

J. Bacterial meningitis was indicated by the presence of the classic symptoms and was confirmed by CSF analysis. Of the 


\section{Open Access Journal of Neurology \& Neurosurgery}

2 patients diagnosed with CSF leakage in this series, one had concomitant bacterial meningitis resolved with intravenous antibiotic therapy, $\chi 2$ is 4.1379 and $p$-value is 0.041932 at $p$ $<0.05$ which is significant.

K. There was one death in this series (mortality rate, 3\%), $\chi 2$ is 14.4828 and $p$-value is 0.000141 at $p<0.05$, which was due to respiratory failure.

\section{Discussion}

A. In our study, acoustic neuroma constituent of about (70\%), and meningioma (20\%) and those readings are close to the study made by Thaba BK et al. BSMMU, Dhaka where acoustic neuroma represents $77 \%$ and Meningioma $15 \%$ [6].

B. Mainly vertigo and tinnitus are the main presentations in our study, $76.6 \%$ and $46.6 \%$ respectively as most of our patients $70 \%$ referred from both neurologist and otolaryngologist. In the literature, reports of balance disorder in vestibular schwannoma schwannoma vary widely. Some authors maintain it may be the presenting symptom in $15 \%$ of cases. Continuous or intermittent tinnitus with concomitant hearing loss is present in approximately $90 \%$ of cases, and is nearly always unilateral [7].

C. Tinnitus which has generally been found in association with hearing loss in other series like the one of Moffat et al., and Thomas NW, although others have also pointed out that it is also an infrequent complaint in non-acoustic cerebellopontine angle lesions [8]. We have found $46.6 \%$ of cases of vertigo such as have been reported by Lalwani AK et al. [6-9].

D. Suboccipital retrosigmoid approach was the standard procedure in all cases described in our study, this

E. Reflects our neurosurgical department standards and the familiarity of the approach access. Similarly Glasscock et al. reported on the retro mastoid and middle fossa approaches in 161 selected patients. They found a lower incidence of temporary facial nerve paresis using the retrosigmoid approach [10]. Mazzoni et al. reported on a selected series of 90 of 300 patients operated on using the retro mastoid approach for a trial of preservation of hearing. The facial nerve was preserved in 99\%, with completely normal function in $78 \%$. The cochlear nerve was anatomically preserved in $96 \%$ and functionally in 44\% [11].

F. Rates of CSF leakage have fallen dramatically according to refinement of surgical techniques. Previously reported rates of $20 \%$ have declined with the use of fat packing into the mastoid region and obliteration of the Eustachian tube and middle ear space [12]. In our series, CSF leaks developed in $6 \%$ of patients, patients with ventricular enlargement where shunted preoperatively with ventriculo-peritoneal shunt also using of fascia tight closure with closing of wound in layers.
This rate is comparable with other recent series that have placed rates at $6-16 \%$ [12]. We found that tumor size can influence the development of CSF leaks. Both Slattery et al. [13] and Brennan et al. [14], found a significant relationship between tumor size and the prevalence of CSF leakage; according to Brennan et al. [14] larger tumors appeared to lead to a greater risk of CSF leak; however, Slattery et al. [13] showed a correlation between surgical approach and CSF leakage rate, with a retrosigmoid approach having the highest frequency (15\%) and middle fossa approach the lowest (5.7\%) [13]. Based on these findings, it can be concluded that tumor size and type of surgical approach are the main factors affecting postoperative CSF leakage.

G. Our study shows a clear correlation between increasing tumor size and worsening facial nerve outcome. This is not surprising, as larger tumors tend to become more intimately involved with the facial nerve or significantly alter its course. Studies show that both the type of surgical approach and tumor size are the main factors significantly affecting postoperative facial nerve function [15]. The anatomical facial nerve preservation rate has been reported to be 80 $90 \%$ [15]. The preservation of facial nerve function has been reported to be $70-80 \%$ for tumors greater than $3 \mathrm{~cm}$ in diameter, removed either by the retrosigmoid [15]. The reported preservation rate of "excellent" function after the removal of large tumors is $42-52.6 \%$ [15]. Which is comparable to our study $50 \%$ for tumors $>20 \mathrm{~mm}$.

H. Bacterial meningitis encountered in one patient in our study who had concomitantly a CSF leak which

I. give attention to the aggressive measures to prevent and to treat the CSF leak both intra and post operatively. Though the $3 \%$ meningitis (one patient) if compared to other studies [16] it's so promising and with high positive predictive value.

J. The 3\% mortality following operation the cause was due to respiratory failure, the patient was heavy smoker with borderline respiratory function test. If compared to figures reported in the literatures, it can be justified taking in consideration, the high percentage of late presentation, the availability of the diagnostic aids the lack of intra-operative monitoring shows that the mortality dropped from $85 \%$ in Hensches cases reported in 1910 to $4 \%$ by Cushing 22 years later [11-17].

\section{Conclusion}

Cerebellopontine angle tumors size influences the development of both intra and posts operative complications operative morbidity and mortality. There is obvious and significant correlation between tumor size and post operative facial nerve outcome, CSF leak with larger C.P.A. tumors yield worse outcomes. 


\section{Open Access Journal of Neurology \& Neurosurgery}

\section{References}

1. Moosa S, Ding D (2015) Role of Stereotactic Radiosurgery in the Management of Cerebellopontine Angle Tumors. Austin J Radiat Oncol \& Cancer 1(1): 1004 .

2. Yadav P, Jantre M, Thakkar D (2015) Magnetic resonance imaging of cerebellopontine angle lesions. Med J DY Patil Univ 8: 751-9.

3. Berkowitz O, Iyer AK, Kano H, Talbott EO, Lunsford LD (2015) Epidemiology and Environmental Risk Factors Associated with Vestibular Schwannoma. World Neurosurg 84(6):1674-1680.

4. Baroncini M, Thines L, Reyns N, Schapira S, Vincent C, et al. Retrosigmoid approach for meningiomas of the cerebellopontine angle: results of surgery and place of additional treatments. Acta Neurochir (Wien) 153(10):1931-1940.

5. Acioly MA, Liebsch M, de Aguiar PH, Tatagiba M (2011) Facial Nerve Monitoring During Cerebellopontine Angle and Skull Base Tumor Surgery: A Systematic Review from Description to Current Success on Function Prediction. World Neurosurg 80(6): e271-e300.

6. CharleTator (2011) Preservation of hearing in patients undergoing excision of acoustic neuromas and other cerebellopontine angle tumors. J Neurosurg.

7. Bento RF, Pinna MH, Neto RVB (2012) Vestibular schwannoma: 825 cases from a 25-year experience. Int Arch Otorhinolaryngol 16(4): 466-475.

8. Mohanty A, Venkatrama SK, Rao BR (2011) experience with cerebellopontine angle dermoid. Neurosurgery 40: 24-29.

9. Elizabeth Bullitt (2011) Intracranial tumors in patients with facial pain. J Neurosurg 22: 11-13.
10. Miklos korvah (2012) Tumors of the cerebellopontine angle. Changing policy of treatment national institute of neurosurgery, Hungary. Neurosurgery review: 243-244.

11. Lanman TH, Brackmann DE, Hitselberger WE, Subin B (2012) Report of 190 consecutive cases of large acoustic tumors (vestibular schwannoma) removed via the translabyrinthine approach. J Neurosurg 90: 617-623.

12. Memari F, Hassannia F, Abtahi SHR (2015) Surgical Outcomes of Cerebellopontine angle Tumors in 50 Cases. Iranian Journal of Otorhinolaryngology 27(78): 29-34.

13. WH Slattery III, S Francis, KC House (2001) Perioperative morbidity of acoustic neuroma surgery. Otology and Neurotology 22(6): 895-902.

14. JW Brennan, DW Rowed, JM Nedzelski, JM Chen (2001) Cerebrospinal fluid leak after acoustic neuroma surgery: influence of tumor size and surgical approach on incidence and response to treatment. Journal of Neurosurgery 94(2): 217-223.

15. Jan Betka, Eduard Zvěřina, Zuzana Balogová, oliver profant, Josef Kraus, et al. (2014) "Complications of Microsurgery of Vestibular Schwannoma," BioMed Research International 2014: 1-10.

16. Yamakami I, Uchino Y, Kobayashi E, Yamaura A, Oka N (2012) Removal of large acoustic neurinomas (vestibular schwannomas) by the retrosigmoid approach with no mortality and minimal morbidity. J Neurol Neurosurg Psychiatry 75: 453-458.

17. Dubey A, Sung WS, Shaya M, Patwardhan R, Willis B, et al. (2009) Complications of posterior cranial fossa surgery, Surgical Neurology 72(4): 369-375.

\section{Your next submission with Juniper Publishers} will reach you the below assets

- Quality Editorial service

- Swift Peer Review

- Reprints availability

- E-prints Service

- Manuscript Podcast for convenient understanding

- Global attainment for your research

- Manuscript accessibility in different formats

( Pdf, E-pub, Full Text, Audio)

- Unceasing customer service

Track the below URL for one-step submission

https://juniperpublishers.com/online-submission.php 